\title{
Updating Engineering Education in the Southern Cone: Creativity and Innovation
}

\author{
Ricardo L. Armentano ${ }^{1,2}$ \\ ${ }^{1}$ Favaloro University, Buenos Aires, Argentina \\ ${ }^{2}$ National Technological University, Buenos Aires, Argentina \\ Email: armen@ieee.org
}

Received August 31 ${ }^{\text {st }}$,2012; revised September 30 ${ }^{\text {th }}$, 2012; accepted October $15^{\text {th }}, 2012$

\begin{abstract}
Most of our secondary school graduates have poor skills in mathematics and sciences. This negative handicap makes them refractory to study engineering or science, thus reaching a minimum of aspirants. The innovation we foresee and wish to promote across our countries will undoubtedly require of the alumni, who possess solid bases to design and create products with an important added value, in order to satisfy demands and exceed the expectations in this era, where technology evolves very fast. Creativity awakens the power of our numbed imagination; it is boldness, adventure, discovering and learning from change. To provoke creativity, few things are as important as the time that is dedicated to the cross-pollination with other fields. Many countries are revising the programs of scientific education and the application of new pedagogic paradigms that tend to revert the downward trend of enrollments. We propose a palliative measure, consisting of an introductory course that strives for the training of students in the Stokes diagram, called Pasteur quadrant, seeking to concentrate the scientific task according to the existent knowledge concepts, in the fact that engineering is the motor of innovation, through increasing and consolidating the creative process, teaching them to think and stimulating their critical mind by means of peer teaching.
\end{abstract}

Keywords: Engineering Education; Teaching for Creativity; Innovation

\section{Introduction}

That a nation needs to create wealth to be thriving is a truism. Cartesian essays and exuberant speeches assert that such wealth is reached through added value: integrating knowledge to products and processes, which are later sold worldwide. However, the key question is: how does research in universities contribute to the creation of wealth? The excellence in science and engineering research in universities is linked to the creation of wealth in the economy of a country in three ways:

- by supplying students who graduate and add up-to-date knowledge in the top areas of science and engineering, taking into account that their instructors are creators of knowledge in those areas themselves;

- through the establishment of joint research partnerships between universities and businesses, to be able to develop innovative products and processes, and guarantee their rapid insertion into the markets;

- through inventions developed by basic research, an indisputable element of innovation, which become commercialized throughout the country.

Thinking linearly — and quite naively—a stronger R\&D promotion will result in more innovation in all areas of the regional and national industry, with more international and regional presence of these local innovations in goods and services. It would undoubtedly strengthen prosperity by creating wealth, both individual and collective, thus increasing investments in support of our values: health, infant welfare, education, environment, etc., achieving a higher standard of living in the country. But reality dictates that this trajectory is as linear and sim- ple as whistling in the wind.

Bernardo A. Houssay, one of the three Nobel laureates of Argentina, warned about the three main factors that hinder progress (Houssay, 1952). He said the first and most powerful was misoneism: the resistance to anything new, with eagerness to avoid the innovation that inevitably comes from each scientific advance. The second was the excessive concern for immediate application, an idea common to backward societies, or a sign of decadence in developed ones. Last was the local, professional or nationalist pride; a mix of ignorance, immaturity and selfdefense of the mediocre.

The great challenge of the present University is to ensure a microclimate where the best science and technology can be exercised, and, at the same time, to conduct students to the complete development of their potential as individuals, citizens and workers; to put ideas into action; to generate new understandings concomitant to the use of technology, the paradigm of the research oriented to innovation; to pursue the welfare of society and to improve the life of people through a continuous advance in quality, cost reduction and the conservation of the environment. This endeavor is only possible when distinguished faculty and talented students are confined under adequate pressure and temperature conditions, incorporating a hallmark, mens et mania, acting as a catalyst in this reaction (Keyser, 2011). And fundamentally, assuming individual and institutional maturity to judge and appreciate a culture that celebrates rareness, the ability to choose, independence, entrepreneur spirit, concentration, creativity and passion (Keyser, 2011). But overall, to sustain this culture with a high degree of tenacity, dealing with the undeniable truth: most of our second- 
dary school graduates have poor skills in mathematics and sciences, worsening the uncertainty of teenagers, the weakest link in the social chain, but nevertheless the strongest in terms of vital energy. Let us not forget that teenagers carry the troubles of our civilization in a very intense manner (Morin, 2011). This negative handicap makes them refractory to study engineering or science, thus reaching a minimum minimorum of aspirants. Whereas in China and Japan more than two thirds of university students choose to study Science or Engineering, in the EU $36 \%$ of students do, and in the USA, $24 \%$. According to unofficial data, in Argentina only 8\% of students choose Engineering, IT, Physics or Mathematics degrees, whereas $40 \%$ is enrolled in Social Sciences, Psychology or Philosophy degrees. It is said that Argentina produces five times more psychologists than engineers (Oppenheimer, 2011). In 2010, in Uruguay, 26\% of students chose Liberal Arts related degrees, $19 \%$ of students chose Economics or Business Administration, and only 8.2\% techno-scientific degrees. China, as well as India, is creating a techno-scientific globalized elite, capable of competing with the most industrialized countries. Furthermore, there is a great amount of Asian students in universities in Europe and the USA. In the meantime, the number of South American students, studying locally or abroad, is at a standstill or decreasing. It is noteworthy that this reality occurs as all of the achievements of the 20th century change our habitat. So many complex accomplishments have subliminally become a part of our daily lives, that engineering and-above all—engineering research are taken for granted and go unnoticed, although without them, we believe, the world would be less accessible, poorer and, above all, less interesting.

\section{Focus on Innovation}

What do we understand by Engineering Research? It is simply the motor of innovation. In a global economy driven by knowledge, technological innovation-the transformation of knowledge into products, processes and services-is essential for competitiveness, for long-term growth of productivity and for wealth creation. The pre-eminence in technological innovation requires leadership in all aspects of engineering: research as a bridge between scientific discoveries and practical applications, the teaching of skills needed to create and exploit knowledge and technological innovation, and the practice of engineering to translate knowledge into innovation, competitive products and services. By combining research with education, we not only seize the creativity of the young, but also their training in analytical thinking and in research methodologies, and their solid knowledge of science and engineering, thus tacitly generating brilliant young teacher researchers. This is how we face the great threat of engineering: the aging of the faculty members' concomitant with the obsolescence of the infrastructure. Engineering professors are rapidly aging, and together with other factors such as the slim financial support of the last years, the absence of long term commitments, the lack of interdisciplinary research and curricular innovation, the vicious circle that sets apart young people from engineering schools strengthens. On the other hand, with the collaboration of the industries and laboratories, universities can gather experts in several disciplines, in order to investigate and satisfy the needs of a certain product or service with a high added value. At the same time, university students can develop their scientific thinking and simultaneously gain comprehension about the forces of the markets through internships and involvement in research projects, development and innovation. The academia-industry interaction, as well as the support of governmental agencies, can create enough resources for engineering universities to be able to modernize their facilities, and by this, making the specialty much more attractive to the new generations, and to engage students to complete their degrees. The installation of laboratories with state-of-the-art technology can enhance the quality of engineering education to a great extent, and create opportunities for thousands of young creative people to contribute to the innovation process. The increase in funding for research in engineering would also create opportunities of attracting talented citizens from all over our countries, as well as talented students from all over the world, to join our doctorate programs. The innovation we foresee and wish to promote across our countries will undoubtedly require of the alumni, who possess solid bases to design and create products with an important added value, in order to satisfy demands and exceed the expectations in this era, where technology evolves very fast. This is because they posses skills to develop themselves in domains that may have not existed at the time they completed their degrees, and to face a context of global crisis, but nevertheless of great opportunities.

\section{Focus on Creativity}

We are convinced that many findings in the field of Engineering and Science in general, which have had great impact in humanity, are the result of serendipity, i.e. the receptive ability to discover, unexpectedly, something valuable. Creativity awakens the power of our numbed imagination; it is boldness, adventure, discovering and learning from change. Creativity may seem to be magic, a supernatural power, denied to many mortals and granted to a few, for them to imagine what has never existed before. But creativity is not magical; it is not a genetic attribute or a blessing of the angels, it is ability! Anyone can learn to be creative and to benefit the most from it. The science of creativity is a relatively new concept. Years ago, imagination was compared to a superior act. To be creative meant to have a direct link with the muses. Even in this modern era, scientists have paid little attention to the sources of creativity; however, during the last decade, it has started to change. Nowadays, the word creativity is used as a generic term to name several cognitive tools, each applying to certain issues, conditioning the action in a particular way. New researches also suggest that creative thinking is the best way of approaching the most difficult problems. We tend to assume that experts are creative geniuses in their fields. However, the great advances often depend on the naïve audacity of the profane. To provoke creativity, few things are as important as the time that is dedicated to the cross-pollination with other fields. Many countries are revising the programs of scientific education and the application of new pedagogic paradigms that tend to revert the downward trend of enrollments. A key factor of this trend is the public perception that science does not involve a creative effort. The attempts of reformulating the public perception tend to center themselves in the primary and secondary education, but they do little to face the continuous drop in quality and originality of the intellectual production further than secondary school (Schmidt, 2011). The overcoming of the systematic devaluation of science requires valuing the complex, dynamic and stochastic interaction of the sociocultural, psychological and cognitive factors that drive 
human creativity. Looking at creativity from this point of view highlights the constraint that exists between perception and practice, which limits the opportunities for students, science professors and scientists (Schmidt, 2011).

\section{Techno-Economic Development vs. Prosperity}

Let us agree that a new Trinity (Morin, 2011) governs the social paradigm that welcomes our fresh graduates today: globalization, westernization and development. The techno-economic development is supposed to be the driving force of prosperity and welfare, the general improvement of quality of life, the reduction of inequalities, social harmony and democracy. Growth is conceived as the evident and infallible motor of development, and development is conceived as the evident and infallible motor of growth (Morin, 2011). However, let us agree that development is a complex, ambivalent process, both positive and negative. Its most irreducible defenders state that it has drawn prosperity to diminished areas across the whole planet, giving them access to the western life standards, allowing them to have individual autonomy free from the unconditional authority of family, access to marriage by choice and not by force, freedom of sexual orientation, consumption of goods unknown to them until then, all result of the approach of technology. On the other hand, detractors of development state that the consumer intoxication and the imaginary component of wishes have grown, as well as insatiable needs are constantly renewed. Undoubtedly, development has exacerbated the dark side of consumerism: self-centeredness, self-justification and eagerness for profit. Development establishes a way of organizing society and minds, where hyper-specialization compartmentalizes people; the whole, the global and solidarity are lost of sight. Furthermore, hyper-specialized education replaces old ignorance with a new blindness; it maintains the illusion that rationality determines the development, which confuses technological rationalism with human rationalism (Morin, 2011).

\section{Current Paradigm of Engineering}

The key is to adhere to the current paradigm of engineering, where projects more than disciplines define the terms of the engagement, and the limits between science and engineering become fuzzy (Armentano, 2012). A big part of current biology projects force biologists to think as engineers, testing systems and mechanisms, worrying about quality control and building large technical systems. This space is a circle of exchange, an intermediate domain where procedures can be locally coordinated and techno-science exchange is produced, eliminating boundaries, developing interfaces and flowing in both directions. It is where discovering - the paradigm of science-and solving problems - the paradigm of engineering - are blended, fundamentally because the mission of engineering has been transformed since the dominant issues do not involve conquering nature, but the creation and management of an alreadyexisting habitat (Armentano, 2012).

An important tool is the increasing role of information technology in the construction of a language, common to both disciplines. A large number of engineers work with symbols and models, and currently machines work by processing information rather than matter. Engineering is no longer an applied science. It has developed its own theory, with practitioners who never build objects and researchers who go further than the usually known experiences. To be able to achieve this adaptation, we engineers must reinvent ourselves to work in a hybrid world where technology, science, humanism and other tendencies fuse and interconnect. Consequently, engineering becomes a profession whose limits are not specified, and where technology becomes science, art and management, widening the scope of its institutional mission (Armentano, 2012).

\section{Discussion}

In order to strictly define the strategic ideas that have led to innovation, we turn to the analysis of the upper-right quadrant of the Stokes diagram, called Pasteur quadrant (Stokes, 1997), seeking to concentrate the scientific task according to the existent knowledge, centered in innovative projects that reset the paradigms and the manner of deal with the different disciplines, i.e. to approach issues in a way that generates a new understanding as well as a new usefulness, which is how current research engineering should be understood, as opposed to the old paradigm of basic sciences vs. applied sciences. In this master idea, innovation has a central dimension (Armentano, 2012). This is a holistic challenge, which consists in a new way of learning, innovating, communicating and shearing with a creative attitude that represents quality of perception; and intelligent action that allows us to overcome conflicts with a richness of alternatives that each situation offers us.

\section{Proposal}

Our ideas are summarized in Table 1. We are proposing to modify the format of introductory courses, in strictly methodological terms, by making them more interactive than the regular conference-like course (Mazur, 1997). This methodology has been applied for the last 5 years during the initial or introductory courses, in which, through a neosocratic approach, fellow students become professors (Mazur, 1997), who are encouraged to develop their creative minds and are oriented towards innovative thinking. The method is to teach asking rather than stating facts, because what is important is the reasoning that leads to the answers. Students should be taught to think. Frequently, the effort of retaining the words of the Master conspires against analysis, logic and reasoning (Brahic, 2012). A university education that does not stimulate the analytical mind and that does not teach how to think is not higher education, but training to submission.

Table 1.

Current methods in engineering and science teaching vs. proposed modified format.

\begin{tabular}{cc}
\hline Current Method & Proposed Method \\
\hline Retaining words & Analyzing, using logic, reasoning \\
Conference-like courses & Interactive courses \\
Stating facts & Asking questions, reasoning the answers \\
Training to submit & Teaching how to think \\
Memorizing equations & Acquiring knowledge \\
Manipulating symbols & Understanding the meaning of symbols \\
Passing exams & Learning \\
\hline
\end{tabular}




\section{R. L. ARMENTANO}

Any person who is formed in scientific education cannot be sensitive to sectarian propaganda or to any kind of intolerance: religious, political or administrative. In our short experience and probably as a result of the reigning culture, most students do not learn, they only memorize equations, data and procedures. The essence is that students learn to manipulate symbols but they do not know what they mean. They are not taught to think, but to pass exams. We think that this is one of the most important reasons of the crisis science schools in general and engineering in particular are going through: low amount of interested people and trouble in understanding and withholding of the students. Professors blame each other. University tells us to blame the Secondary School, Secondary School tells us to blame Primary School. We all can and must contribute to making education better.

\section{Conclusion}

We propose a palliative measure, consisting of an introductory course that strives for the training of students in all of the above-mentioned concepts, but mainly in the fact that engineering is the motor of innovation, through increasing and consolidating the creative process, teaching them to think and stimulating their critical mind by means of peer teaching. They should experience the most relevant aspects of the complementarity towards joint effort, under the precept that each individual uses a small part of their human potential. By approaching the concept of creative society between peers at an early age, students can expand, refine, change or rediscover their individual means, under the umbrella of dignified interdependence. It is true that some collaborations collapse under the weight of individual habits (John-Steiner, 2006). Others bloom under the dynamic and productive pressure of ideas.

\section{Acknowledgements}

I would like to thank Sandra Wray for her help in editing and commenting upon this paper.

\section{REFERENCES}

Armentano, R. L. (2012). Innovation in biomechanics oriented to tissue engineering (Spanish ed.). Saarbrücken: Editorial Académica Española.

Brahic, A. (2012). Science, an ambition for France. Paris: Odile Jacob. Houssay, B. A. (1952). Ciencia e investigación. Science and Research, $8,327$.

John-Steiner, V. (2006). Creative collaboration. New York: Oxford University Press. doi:10.1093/acprof:oso/9780195307702.001.0001

Keyser, S. J. (2011). The MIT nobody knows. Cambridge, MA: MIT Press.

Mazur, E. (1997). Peer instruction: A user's manual. Upper Saddle River, NJ: Prentice Hall.

Morin, E. (2011). The way for the future of humanity. Paris: Fayard.

Oppenheimer, A. (2011). Cuentos chinos (Spanish ed.). Buenos Aires: Debolsillo.

Schmidt, A. L. (2011). Creativity in science: Tensions between perception and practice. Creative Education, 2, 435-445.

Stokes, D. E. (1997). Pasteur's quadrant: Basic science and technological innovation. Washington, DC: Brookings Institution Press. 